\title{
Gender Differences in Perceived Stress Among Childhood Education Lecturers
}

\author{
Anthonia O. Aneke ${ }^{1}$, Anthonia N. Ngwoke ${ }^{1}$, Adaorah Onuorah ${ }^{1}$, Juliana N. Ejiofor ${ }^{1}$, Clara O. Ifelunni ${ }^{1}$, \\ Edith Okpala $^{1}$, Edith Ngozi Ekesionye ${ }^{1} \&$ Lambert Peter Ukanga ${ }^{2}$ \\ ${ }^{1}$ Department of Educational Foundations, University of Nigeria, Nsukka, Enugu State, Nigeria \\ ${ }^{2}$ Department of Philosophy, University of Nigeria, Nsukka, P.M.B. 410001, Enugu State, Nigeria \\ Correspondence: Edith Ngozi Ekesionye, Department of Educational Foundations, University of Nigeria, Nsukka, \\ Enugu State, Nigeria. E-mail: ngozi.ekesionye@unn.edu.ng
}

Received: December 23, 2019 Accepted: February 04, 2020 Online Published: March 22, 2020

doi:10.5539/gjhs.v12n5p61 URL: https://doi.org/10.5539/gjhs.v12n5p61

\begin{abstract}
This study examined the differences in stress perception in a sample of childhood education lecturers in Nigerian Tertiary Institutions by gender. Forty (40) childhood education lecturers across public colleges of education and universities were conveniently sampled for this descriptive survey study. A questionnaire measuring stress perception was used for collecting the research data. Mean, standard deviation and unpaired t-test were used for data collection. Results show that the stress score of the female lecturers was significantly higher than that of the male lecturers in childhood education. Therefore, there is a need for stress management programme among these female lecturers.
\end{abstract}

Keywords: Gender differences, perceived stress, early childhood and childhood education lecturers

\section{Introduction}

Gender as a concept means the roles and the responsibilities in which men and women are created in our families, our societies and our cultures (March, \& Smyth, 2003). One can, therefore, insinuate that according to Baseline concept of gender is a man-made thing. Again, the concept of gender involves equally the expectations held about the personality, ability and likely behaviours of both women and men (femininity and masculinity) (March, \& Smyth, 2003). Gender roles and the outcome are learned behaviour, which can change over time and therefore varies between cultures. Interrogating further, structures of social differences in the society such as; political status, class, ethnicity, physical and mental disability, age and more, are all tools for gender modification (March, \& Smyth, 2003). In line with this, gender roles should be built on equality; the meaningful partnership of male and female and their various roles in the society. The accomplishment of gender equality in and through education remains a vital approach towards the realization of the vision 2030 Agenda for Sustainable Development (UNESCO, 2018).

Stress and stress perception is a measure of the degree to which circumstances in a life of an individual are determined as stressful (Chan \& La Greca, 2013; Cohen et al., 1983; Siqueira Reis, Ferreira Hino, \&Romélio Rodriguez Añez, 2010). The stress perception is usually measured by the Perceived Stress Scale (PSS), which records have proven to be the most extensively used tool in the psychological measurement of the perception of stress (Chan \& La Greca, 2013). It is equally reported that stress level by gender is an important area of research (Eskay, Arumede, Eneh, \&Aja, 2019).

Gender and stress research has increasingly focused on the differences of sex in neuroendocrine, autonomic, or behavioural reaction to stress (Handa \& Chung, 2007). In gender and stress research, many studies make use of animal models to show hormonal and behavioural stress reactions, their aim is to control the kind of stress administered and at the same time checking out the prior stress experience (Handa\& Chung, 2007). Ultimately, a better understanding of the stress level among humans is essential in the advancement of efficient management for stress-related illness. The main purpose of this study was to examine the differences in stress perception in a sample of childhood education lecturers in Nigerian Tertiary Institutions by gender. 


\section{Method}

The approval to conduct this study was granted by the Faculty of Education Research Ethics Committee, University of Nigeria, Nsukka. Forty (40) childhood education lecturers across public colleges of education and universities in South-east Nigeria were conveniently sampled for this descriptive survey study. A 10-item questionnaire measuring stress perception by Cohen et al. (1983) was used for collecting the research data. The questionnaire is responded to using the following scale: $0=$ Never, $1=$ Almost Never, $2=$ Sometimes, $3=$ Fairly Often, and $4=$ Very Often. Cronbach alpha reliability was 0.86 . Informed consent was obtained orally. A research assistant helped in gathering the data from the lecturers. Mean, standard deviation and unpaired t-test were used for data collection. Our result was interpreted as being significant at $\mathrm{P} \leq .05$.

\section{Results}

Table 1. Results of overall mean stress score among childhood education lecturers

\begin{tabular}{llllll}
\hline Stress perception & $\mathbf{N}$ & $\mathbf{M}(\mathbf{S D})$ & $\boldsymbol{T}$ & $\boldsymbol{p}$ & BCa 95\% Confidence Interval \\
\hline Total & 40 & $32.00(4.79)$ & 42.177 & .000 & $30.70-33.34$ \\
\hline
\end{tabular}

Results in Table 1 show that the overall stress score of the lecturers was significantly high in childhood education lecturers, mean $=32.00 \pm 4.79, \mathrm{t}(39)=42.177, P=.000, \mathrm{BCa} \mathrm{CI}=30.70-33.34$.

Table 2.Stress scores across gender among childhood education lecturers

\begin{tabular}{|c|c|c|c|c|c|c|c|c|}
\hline Stress Scale & Variables & $\mathbf{N}$ & Mean & SD & Mean Difference & $t$ & $P$ & BCa 95\%CI \\
\hline \multirow{2}{*}{ Stress perception } & Male & 17 & 29.35 & 3.371 & \multirow{2}{*}{-4.60358} & \multirow{2}{*}{-3.376} & \multirow{2}{*}{.002} & $27.95-31.12$ \\
\hline & Female & 23 & 33.96 & 4.809 & & & & $31.90-35.83$ \\
\hline
\end{tabular}

Specifically, Table 2 shows that the mean stress score of the female lecturers was significantly higher (33.96 \pm 4.809$)$ than that of the male lecturers(29.35 \pm 3.371$), \mathrm{t}(39)=-3.376, P=.002$ in childhood education. Similarly, the bar chart shown in figure 1 concretised this result with a clear mean difference of 4.60358 .

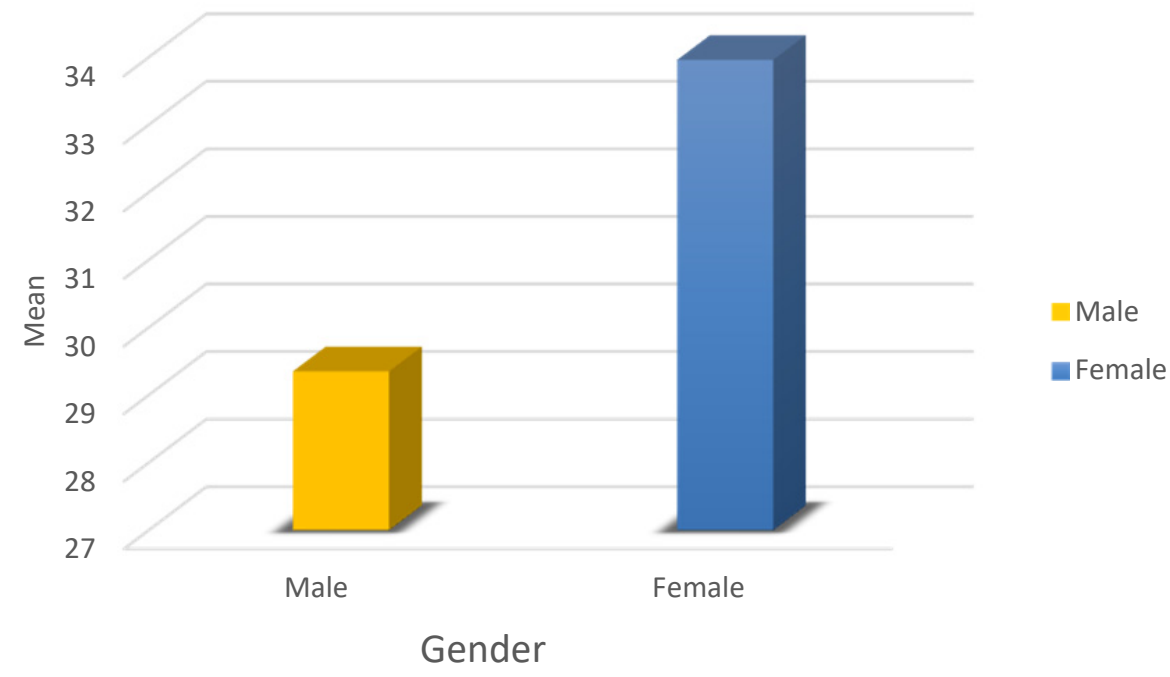

Figure 1. A bar chart showing the mean stress scores across gender among childhood education lecturers

\section{Discussion}

This study investigated the differences in stress perception in a sample of childhood education lecturers in Nigerian Tertiary Institutions by gender. It was found that the stress score of the female lecturers was significantly higher 
than that of the male lecturers in childhood education. There are past studies about gender differences in the perception of levels of stress among male and female workers. A study indicates that male and female workers have conflicting attitudes about the amount and nature of gender discrimination within their work (Dowler \& Arai, 2008). Further, findings added that females experience higher levels of stress (Dowler \& Arai, 2008). Also, a weak relationship was equally reported in the perception of gender-related stress level for female. On the other hand, males who reported on female high level of stress got a lower level of stress experience (Dowler \& Arai, 2008).

It is also noted that there is a high rate of perceived stress among females as compared to their male counterparts (Eskay et al., 2019). Nnabuihe et al. (2012) in Eskay et al. equally showed some level of perceived stress in females compared to their male counterparts. Nnabuihe et al. posit that stress is likely to be profound among females than their male counterparts. The study between gender and reactions to stress shows a significant difference between males and females concerning their reactions to stress (Calvarese, 2015). More females experience higher levels of depression, frustration, and anxiety than their male counterparts when reacting to stress (Calvarese, 2015). Also, more females expressed anger than males as a reaction to stress (Calvarese, 2015). Therefore, there is a need for stress management programme among these female lecturers.

\section{Conclusion}

Stress score of the female lecturers was significantly higher than that of the male lecturers in childhood education. Therefore, there is a need for stress management programme among these female lecturers.

\section{Competing Interests Statement}

The authors declare that there are no competing or potential conflicts of interest.

\section{References}

Calvarese, M. (2015). The effect of gender on stress factors: An exploratory study among university students. Social Sciences, 4(4), 1177-1184. https://doi.org/10.3390/socsci4041177

Chan, S. F., \& La Greca, A. M. (2013). Perceived Stress Scale (PSS). Encyclopedia of Behavioral Medicine, 1454-1455. https://doi.org/10.1007/978-1-4419-1005-9_773

Cohen, S., Kamarck, T., \&Mermelstein, R. (1983).A global measure of perceived stress. Journal of Health and Social Behavior, 24, 386-396. https://doi.org/10.2307/2136404

Dowler, K., \& Arai, B. (2008). Stress, Gender and Policing: The Impact of Perceived Gender Discrimination on Symptoms of Stress. International Journal of Police Science \& Management, 10(2), 123-135. https://doi.org/10.1350/ijps.2008.10.2.81

Eskay, M., Arumede, F. I., Eneh, A. U., \& Aja, J. O. (2019).Gender Differences in Stress Perception among Special Education Students. Global Journal of Health Science, 11(14), 115-118. https://doi.org/10.5539/gjhs.v11n14p115

Handa, R. J., \& Chung, W. C. J. (2007). Gender and Stress.In Encyclopedia of Stress. https://doi.org/10.1016/B978-012373947-6.00170-7

March, C., \& Smyth I., M. M. (2003). Baseline definitions of key concepts and terms. UNESCO's Gender Mainstreaming Implementation Framework, (April), 1-3.

Siqueira Reis, R., Ferreira Hino, A. A., \&Romélio Rodriguez Añez, C. (2010). Perceived Stress Scale: Reliability and Validity Study in Brazil. Journal of Health Psychology, 15(1), 107-14. https://doi.org/10.1177/1359105309346343

UNESCO. (2018). Achieving gender equality in education: don't forget the boys. Global Education Monitoring Report.

\section{Copyrights}

Copyright for this article is retained by the author(s), with first publication rights granted to the journal.

This is an open-access article distributed under the terms and conditions of the Creative Commons Attribution license (http://creativecommons.org/licenses/by/4.0/). 